\title{
New resin composites used to restore both anterior and posterior teeth
}

\author{
Antonio Cerutti ${ }^{1}$ and Nicola Barabanti ${ }^{2}$
}

\begin{abstract}
Over the last few years, the advancements made in the field of adhesive techniques have significantly modified operative techniques, from cavity preparation to final restoration. On one hand, a predictable bond between restoration and dental tissues allows us to operate with very conservative techniques, saving sound dental tissue; on the other hand, it must be considered that such procedures are not simple. Additionally, it is easy to observe that all of our everyday dental practice is strictly influenced by the type of material and techniques used. Knowing such procedures as well as adhesive mechanisms, quality of sound dental tissue and its conservation - both in vital and endodontically treated teeth - is now considered significantly relevant for restorative purposes.
\end{abstract}

The success of recent resin composites is based both on their very good aesthetic qualities and on their improved physical patterns. Dentists therefore have the opportunity to use new composites to restore not only anterior but also posterior teeth.

There is now the availability of masses simulating dentinal tissue and masses simulating enamel tissue. These two types of masses, if skilfully used, are determinant in the correct reproduction of 'dental colour'. However, adequate masses management in matters of colour, thickness and quality is not so easy. In restoring the anterior sector we have to face the problems of mimicry between dental element and restoration, of correct morphological reproduction, and of consequent composite material stratification.

Hybrid composites represented a further step forwards with respect to the mechanical properties of composite materials, posterior restorations need to support occlusal forces, so resin composites, improved in their mechanical qualities, are now able to behave as dental tissues. Micro and nano fillers give the necessary resistance to

${ }^{1}$ Director: Professor, Department of Restorative Dentistry, ${ }^{2}$ Associate Professor, University of Brescia

doi:10.1038/sj.bdj.4811180

๑) British Dental Journal 2004; 196: 505 compression and easy handling properties, adhesives, if correctly performed, can generate forces as much as $20 \mathrm{MPa} \mathrm{cm}-2$ but all these need good knowledge of the techniques.

A clinical example of an anterior and a posterior composite restoration are shown below, both in vital and in devitalised teeth.

It easy to see how, thanks to these new materials, it is possible to re-create aesthetic characteristics and morphological form, by doing a mimesis with the remainder tissues.

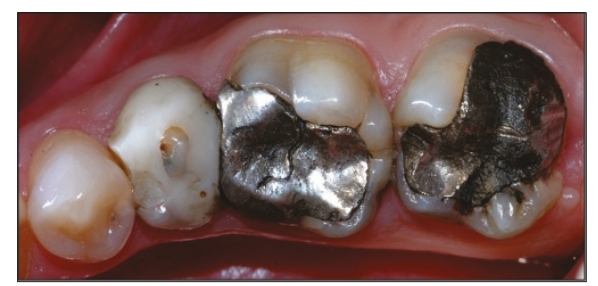

Old amalgam posterior restorations

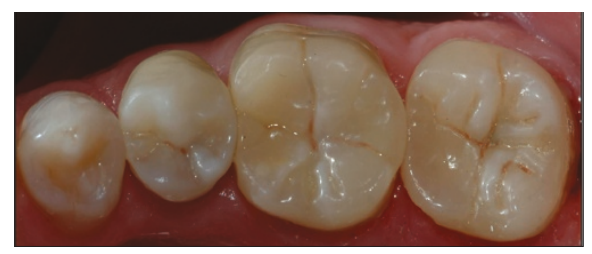

Rehabilitation of posterior teeth with the use of composite materials

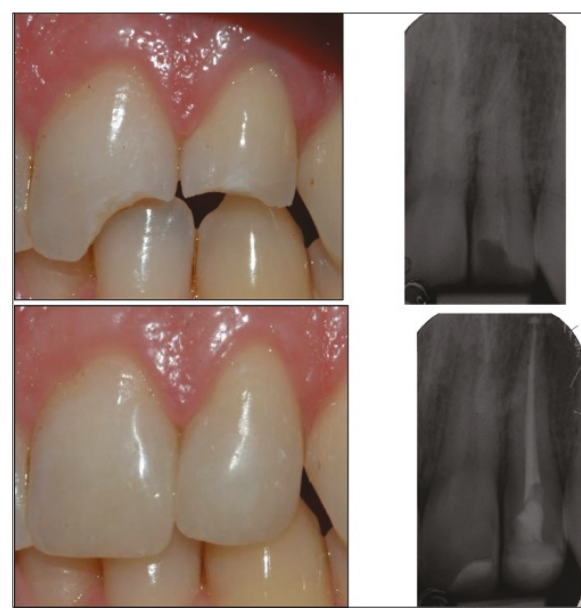

Composite restorations in anterior vital and devitalized teeth

The British Dental Conference \& Exhibition 2005 is being held at the Glasgow SECC between Thursday 19th and Saturday 21st May 2005

Contact: DMS (Delegate Management Services) for further information:

Tel: 08701666625 or +44 (0) 1252771425 (overseas)

Fax: 08705228890 or +44 (0) 1252771790 (overseas)

For the latest update on the agenda and to download the programme visit: www.bda-events.org 